\title{
DESIGN OF A NOVEL CURRENT BALANCED VOLTAGE CONTROLLED DELAY ELEMENT
}

\author{
Pooja Saxena ${ }^{1}$, Sudheer K. $M^{2}$, V. B. Chandratre ${ }^{2}$ \\ ${ }^{1}$ Homi Bhabha National Institute, Mumbai 400094 \\ ${ }^{2}$ Electronics Division, Bhabha Atomic Research Center, Trombay, Mumbai 400085
}

\begin{abstract}
This paper presents a design of fast voltage controlled delay element based on modified version of low noise Current Balanced Logic (CBL). This delay element provides identical rising and falling edge delays controlled by the single control voltage. The post layout tunable delay range is from 140 ps to 800 ps over control voltage range of 0 to $2.1 \mathrm{~V}$. An analysis for the delay element is also presented, which is in agreement with the simulated delays. A Delay Lock Loop (DLL) is designed using this delay element to verify its performance.
\end{abstract}

\section{KEYWORDS}

Current Balanced Logic (CBL), Source Coupled Logic (SCL), Current Starved Inverter (CSI), Delay Lock Loop (DLL), Phase Lock Loop (PLL)

\section{INTRODUCTION}

Delay Element (DE) is a vital block in Delay Lock Loop (DLL) [1], Phase Lock Loop (PLL) [2], microprocessor and memory circuits [3] and Time-to-Digital Converters [4]. The aim is to design a delay element, which assists in time interval (TI) measurement [4] with high resolution $(<200$ ps) for High Energy Physics (HEP) experiments. A variety of DEs already has been reported in the literature [5] with their merits and limitations. The Current Starved Inverter (CSI) is used as a delay element in time measurement circuits. This structure ensures wide delay regulation range and low power consumption. The reported delay using CSI is 244 ps [6] in $0.35 \mu \mathrm{m}$ CMOS process.

Transmission gate based delay element [5] is fast due to relatively low resistive path between input and output. It is power and area efficient and has full swing output. However, the delay increases quadratically with the number of cascaded transmission gates [7]. Differential DE based on low noise Source Coupled Logic (SCL) [8] [9] [10] mitigates the common mode noise, which is prevalent in CSI. They are fast but have partial output swing and are power inefficient due to the high static current. In addition, they require a complex bias circuitry for delay variation.

This paper presents a design of voltage controlled delay element based on modified version of Current Balanced Logic (CBL) [11] and is referred here as Modified CBL (MCBL) delay element. The salient features of this delay element are identical delays in the rising and falling edge transitions, high speed, area efficient, less contribution in the generation of 'di/dt' switching noise and low power consumption as compared to other architectures of differential delay elements.

The paper is organized in the following sections: In section 2, an overview of current balanced logic and architecture of MCBL DE is presented. A detailed analysis of the circuit is also provided. The simulation results are compared with the analytical results. In section 3, a design of 
International Journal of VLSI design \& Communication Systems (VLSICS) Vol.5, No.3, June 2014

Delay Lock Loop (DLL) has been presented using MCBL delay element. In Section 4, post layout simulation results are presented. In section 5, conclusions are drawn.

\section{CURRENT BALANCED LOGIC (CBL)}

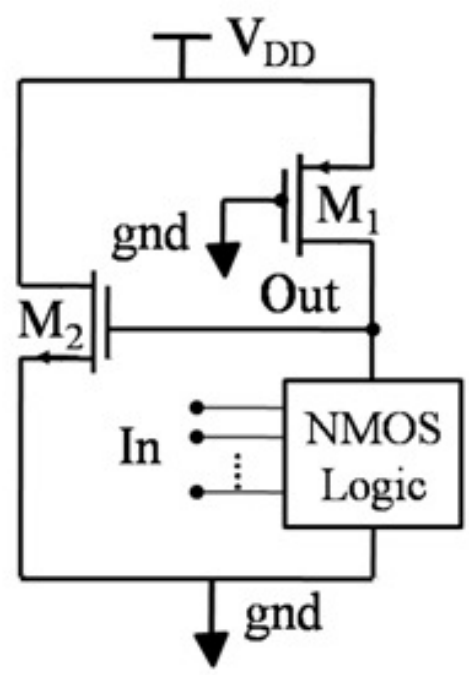

Figure 1. Current Balanced Logic Circuit

Current Balanced Logic (CBL) [10] is the low noise logic family that reduces 'di/dt' switching noise. The noise reduction technique aims to keep the supply current steady. This scheme modifies pseudo NMOS logic by adding the NMOS transistor ' $\mathrm{M}_{2}$ ' as shown in Figure 1. When NMOS logic block is on, the output node 'Out' is pulled down, which keeps $\mathbf{M}_{2}$ in cut-off operating region and there is a static supply current through $\mathrm{M}_{1}$. When NMOS logic block is off, $M_{2}$ is in saturation and draws the same supply current assuming $M_{1}$ and $M_{2}$ are well matched.

\subsection{Architecture of MCBL delay element}

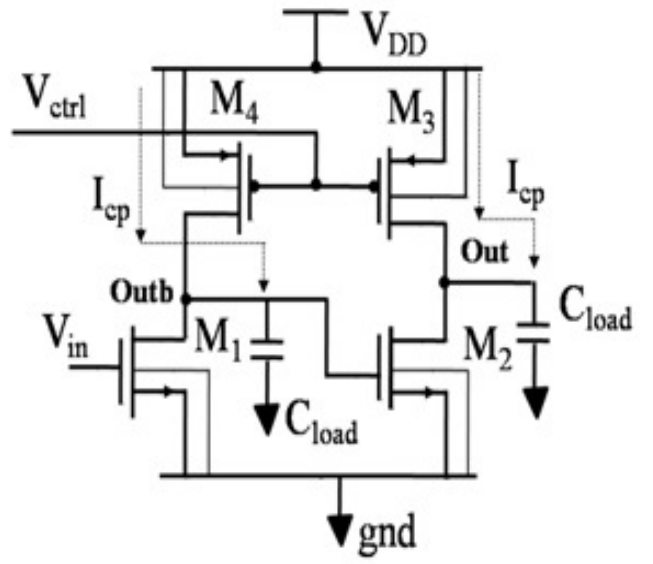

(a)

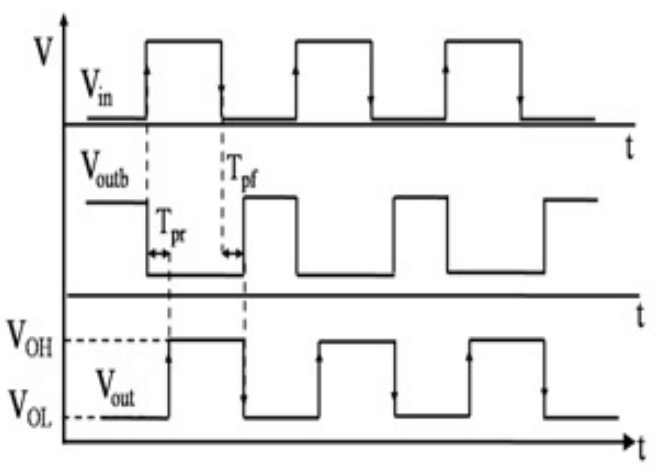

(b)

Figure 2. MCBL Delay element (a) Schematic Diagram (b) Timing Diagram 
International Journal of VLSI design \& Communication Systems (VLSICS) Vol.5, No.3, June 2014

Figure 2 represents the schematic and timing diagram of MCBL delay element. The amount of charging current ' $\mathrm{I}_{\mathrm{cp}}$ ' through PMOS transistors ' $\mathrm{M}_{3}$ ' and ' $\mathrm{M}_{4}$ ' controls the rising and falling edge propagation delays respectively. The current ' $\mathrm{I}_{\mathrm{cp}}$ ' is determined by the control voltage ' $\mathrm{V}_{\text {ctrl }}$ '. Both rising ' $\mathrm{T}_{\mathrm{pr}}$ ' and falling ' $\mathrm{T}_{\mathrm{pf}}$ ' edge delays are identical as PMOS ' $\mathrm{M}_{3}$ ' and ' $\mathrm{M}_{4}$ ' as well as NMOS ' $\mathrm{M}_{1}$ ' and ' $\mathrm{M}_{2}$ ' are matched transistors, the nodes 'Out' and 'Outb' face the same capacitive load $\left(\mathrm{C}_{\text {load }}\right)$.

As shown in Figure 2(b), when rising edge transition of ' $V_{\text {in }}$ ' clock is applied, the 'Outb' node pulls down. The NMOS transistor $\mathrm{M}_{2}$ enters in the cut-off region and PMOS ' $\mathrm{M}_{3}$ ' starts pulling up the node 'Out' by charging the load capacitance ' $\mathrm{C}_{\text {load }}$ ' using ' $\mathrm{I}_{\mathrm{cp}}$ '. When falling edge transition of $V_{i n}$ is applied, ' $M_{1}$ ' is turned off. Subsequently ' $M_{4}$ ' starts pulling up the node 'Outb'. This turns on ' $\mathbf{M}_{2}$ ', which pulls down the node 'Out'. The pull down is fast as aspect ratio 'W/L' of NMOS is designed to be higher than PMOS transistors. The signals $\mathrm{V}_{\text {in }}$ and $\mathrm{V}_{\text {out }}$ are of same polarity with identical rising ' $\mathrm{T}_{\mathrm{pr}}$ ' and falling ' $\mathrm{T}_{\mathrm{pf}}$ ' edge delays. The variation in the supply current is small as equal current path is maintained in rising and falling edge transitions. This ensures the current balancing.

This MCBL DE can be interfaced to the standard cells available in the PDK (Process Design Kit) owing to its large output swing. It is fast as compared to CSI, shown in Figure 3, as the resistance of charging path of capacitive load ' $\mathrm{C}_{\text {load }}$ ' is less. There is only one transistor ' $\mathrm{M}_{3}$ ' in the charging path for MCBL while in CSI, there are two series connected transistors $\mathbf{M}_{7}$ and $\mathbf{M}_{8}$. In the cascaded delay line, the MCBL DE faces a single transistor $\left(\mathrm{M}_{1}\right)$ load (gate capacitance) as compared to two transistors $\left(\mathrm{M}_{6}\right.$ and $\left.\mathrm{M}_{7}\right)$ load in CSI. This further reduces the propagation delay of MCBL DE. The static current is small as compared to differential delay elements. Further, this DE has wide delay tuning range with respect to control voltage.

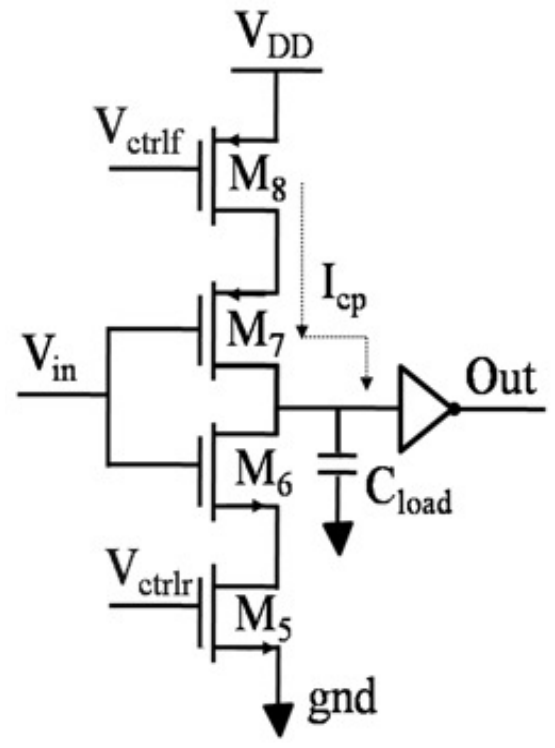

Figure 3. Schematic Diagram of CSI

\subsection{Analysis of the MCBL delay element}

This section describes the equation for propagation delay as well as output voltages $\mathrm{V}_{\mathrm{OL}}$ (maximum output voltage in logic ' 0 ') and $\mathrm{V}_{\mathrm{OH}}$ (minimum output voltage in logic ' 1 '). 
International Journal of VLSI design \& Communication Systems (VLSICS) Vol.5, No.3, June 2014

\subsubsection{Calculation of $\mathrm{V}_{\mathrm{OL}}$ and $\mathrm{V}_{\mathrm{OH}}$}

To ensure the compatibility of DE to be interfaced with the standard cells, it is required to calculate $\mathrm{V}_{\mathrm{OL}}$ and $\mathrm{V}_{\mathrm{OH}}$ over a control voltage range. In the calculation of $\mathrm{V}_{\mathrm{OL}}$, it is assumed that $\mathrm{V}_{\text {in }}$ is less than the threshold voltage ' $\mathrm{V}_{\mathrm{tn}}$ ' of $\mathrm{M}_{1}\left(\mathrm{~V}_{\text {in }}<\mathrm{V}_{\text {tn }}\right)$ (Figure 2(a)). The NMOS transistor $\mathrm{M}_{1}$ is turned off and subsequently $M_{2}$ is turned on. There is a static current through $M_{3}$ and $M_{2}$. The expression of $\mathrm{V}_{\mathrm{OL}}$ is derived by applying $\mathrm{KCL}$ at node 'Out':

$I_{M 3(\text { saturation })}=I_{M 2(\text { linear })}$

$\frac{1}{2}\left(\mu_{p}\right)\left(C_{o x}\right)\left(\frac{W}{L}\right)_{M 3}\left(V_{c t r l}-V_{D D}-V_{t p}\right)^{2}=\left(\mu_{n}\right)\left(C_{o x}\right)\left(\frac{W}{L}\right)_{M 2}\left(\left(V_{D D}-V_{t n}\right) V_{o u t}-\frac{V_{o u t}{ }^{2}}{2}\right)$

where, $\mu_{\mathrm{n}}$ and $\mu_{\mathrm{p}}$ are the mobility of electrons and holes in $\mathrm{cm}^{2} /$ Volt-sec, $\mathrm{C}_{\mathrm{ox}}$ is oxide capacitance per unit area, W/L is aspect ratio of transistors, and $\mathrm{V}_{\mathrm{tn}}$ and $\mathrm{V}_{\mathrm{tp}}$ are threshold voltage of NMOS and PMOS transistors respectively. On simplification, equation (2) can be written as-

$A\left(V_{c t r l}-V_{D D}-V_{t p}\right)^{2}=2\left(V_{D D}-V_{t n}\right) V_{\text {out }}-V_{\text {out }}^{2}$

Where, $A=\frac{\mu_{p}\left(\frac{W}{L}\right)_{M 3}}{\mu_{n}\left(\frac{W}{L}\right)_{M 2}}$

On simplifying, we get a quadratic equation (4) in terms of $\mathrm{V}_{\text {out }}$ :

$V_{\text {out }}^{2}-2 V_{\text {out }}\left(V_{D D}-V_{t n}\right)+A\left(V_{c t r l}-V_{D D}-V_{t p}\right)^{2}=0$

The roots of quadratic equation $\mathrm{ax}^{2}+\mathrm{bx}+\mathrm{c}=0$ are given by:

$$
x=\frac{-b \pm \sqrt{b^{2}-4 a c}}{2 a}
$$

Equating the corresponding coefficients of equation (4) and (5) we get:

$$
V_{\text {out }}=\left[V_{D D}-V_{t n} \pm S\right] \text { Where, } S=\sqrt{\left(V_{D D}-V_{t n}\right)^{2}-A\left(V_{c t r l}-V_{D D}-V_{t p}\right)^{2}}
$$

Expression for $\mathrm{V}_{\mathrm{OL}}$ is given with negative root of above quadratic equation as value of $\mathrm{V}_{\mathrm{OL}}$ should be in between 0 to $\mathrm{V}_{\mathrm{DD}}$.

$$
V_{\text {out }}=V_{O L}=V_{D D}-V_{t n}-S
$$

$\mathrm{V}_{\mathrm{OL}}$ is designed to be low by keeping the aspect ratio of NMOS transistors $\left(\mathrm{M}_{1}\right.$ and $\left.\mathrm{M}_{2}\right)$ higher than PMOS transistors $\left(\mathrm{M}_{3}\right.$ and $\left.\mathrm{M}_{4}\right)$. To calculate $\mathrm{V}_{\mathrm{OH}}$, the assumption is $\mathrm{V}_{\mathrm{in}}>\mathrm{V}_{\mathrm{tn}}$. Consequently ' $\mathrm{M}_{2}$ ' is turned off so that $\mathrm{I}_{\mathrm{M} 2}=0$. By applying $\mathrm{KCL}$ at node 'Out', we get:

$$
\begin{aligned}
& I_{M 3}=I_{M 2}=0 \\
= & \frac{K_{p} W}{2 L}\left\{2\left(V_{c t r l}-V_{D D}-V_{t p}\right)\left(V_{o u t}-V_{D D}\right)-\left(V_{o u t}-V_{D D}\right)^{2}\right\}=0
\end{aligned}
$$

The only valid solution of equation (7) is $\mathrm{V}_{\text {out }}=\mathrm{V}_{\mathrm{OH}}=\mathrm{V}_{\mathrm{DD}}$. In order to verify the analytical equations for $\mathrm{V}_{\mathrm{OL}}$, technological and operating parameters, as shown in Table (1) are used. Figure 4 (a) shows the comparison of simulated and analytical data for $\mathrm{V}_{\mathrm{OL}}$ over the control voltage ' $\mathrm{V}_{\text {ctrl }}$ '. The maximum deviation is $20 \mathrm{mV}$. The values of $\mathrm{V}_{\mathrm{OL}}$ over the entire range of control voltage are small. Therefore, they can be interfaced with the standard cells in the design of DL 
International Journal of VLSI design \& Communication Systems (VLSICS) Vol.5, No.3, June 2014

\subsubsection{Propagation Delay equation}

The aim is to find the rising edge propagation delay ' $\mathrm{T}_{\mathrm{pr}}$ ' (Figure 2(b)) of the circuit with respect to control voltage ' $\mathrm{V}_{\text {ctrl }}$ '. When $\mathrm{V}_{\text {in }}$ is at logic ' 1 ', $\mathrm{V}_{\text {outb }}$ pulls down to $\mathrm{V}_{\mathrm{OL}}$. Consequently, the NMOS transistor $\mathrm{M}_{2}$ enters in the cut-off region. In the calculation explained below, it is assumed that $\mathrm{M}_{2}$ enters in cut-off after a constant delay. It is not modeled to avoid the complexity in the calculation. Assuming negligible current through $\mathrm{M}_{2}$, the current ' $\mathrm{I}_{\mathrm{cp}}$ ' through $\mathrm{M}_{3}$ is used to charge the load capacitance ' $\mathrm{C}_{\text {load }}$ '. The relation between the current ' $\mathrm{I}_{\mathrm{cp}}$ ' and delay ' $\mathrm{T}_{\mathrm{pr}}$ ' is given by equation (8).

$$
T_{p r}=C_{\text {load }} \int_{V_{O L}}^{V_{D D} / 2} \frac{d V_{\text {out }}}{I_{c p}\left(V_{o u t}\right)}
$$

The channel length ' $\mathrm{L}$ ' of PMOS transistor $\mathrm{M}_{3}$ is designed to be $0.35 \mu \mathrm{m}$. The value of $\mathrm{V}_{\text {DSAT }}$ is $1.7 \mathrm{~V}$ in $0.35 \mu \mathrm{m}$ AMS CMOS process. It is a good approximation to assume velocity saturated behavior from $\mathrm{V}_{\mathrm{OL}}$ to $\mathrm{V}_{\mathrm{DD}} / 2$. The current $\mathrm{I}_{\mathrm{cp}}$ in velocity saturation operating region is given by equation (9), where $K_{p}$ is the gain factor for PMOS transistor and $\lambda$ is channel length modulation factor.

$$
\begin{aligned}
I_{c p}=I_{s d}=-I_{d s} & =-\frac{K_{p}}{2}\left(V_{c t r l}-V_{D D}-V_{t p}\right)\left(1+\lambda\left(\mathrm{V}_{\mathrm{out}}-\mathrm{V}_{\mathrm{DD}}\right)\right) \\
& =\frac{K_{p}}{2}\left(V_{D D}-V_{c t r l}+V_{t p}\right)\left(1+\lambda\left(\mathrm{V}_{\mathrm{out}}-\mathrm{V}_{\mathrm{DD}}\right)\right.
\end{aligned}
$$

This equation holds for the transition time of 'Out' node when it attains the voltage $\mathrm{V}_{\mathrm{DD}} / 2$. Substituting this value of current in (8):

$$
\begin{aligned}
& T_{p r}=\frac{2 \times C_{\text {load }}}{K_{p}} \int_{V_{O L}}^{V_{D D} / 2} \frac{d V_{\text {out }}}{\left(V_{D D}-V_{c t r l}+V_{t p}\right)\left(1+\lambda\left(V_{\text {out }}-V_{D D}\right)\right)} \\
& T_{p r}=\frac{2 \times C_{\text {load }}}{K_{p} \times\left(V_{D D}-V_{c t r l}+V_{t p}\right)} \int_{V_{O L}}^{V_{D D} / 2} \frac{d V_{\text {out }}}{\left(1+\lambda\left(V_{\text {out }}-V_{D D}\right)\right)} \\
& T_{p r}=K_{1}\left[\ln \left(1+\lambda\left(V_{\text {out }}-V_{D D}\right)\right]_{V_{O L} / 2}^{V_{D D} / 2} \quad \text { Where, } K_{1}=\frac{2 \times C_{\text {load }}}{\lambda K_{p}\left(V_{D D}-V_{c t r l}+V_{t p}\right)}\right. \\
& T_{p r}=K_{1} \ln \left[\frac{\left(1+\lambda\left(\frac{V_{D D}}{2}-V_{D D}\right)\right)}{\left(1+\lambda\left(V_{O L}-V_{D D}\right)\right)}\right]
\end{aligned}
$$

Figure 4(b) shows the comparison of simulated and analytical data for delay $\mathrm{T}_{\mathrm{pr}}$ over control voltage. There is sufficient matching in the analytical and simulated data for usable range of control voltage from $0 \mathrm{~V}$ to $2.1 \mathrm{~V}$. 
International Journal of VLSI design \& Communication Systems (VLSICS) Vol.5, No.3, June 2014

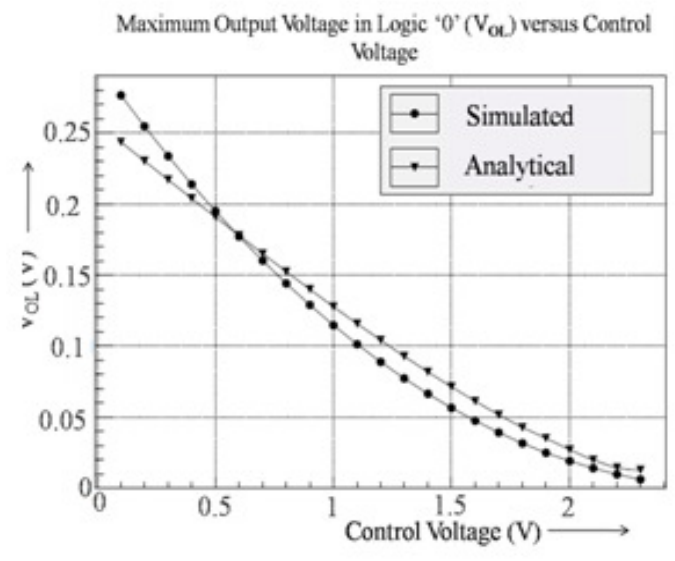

(a)

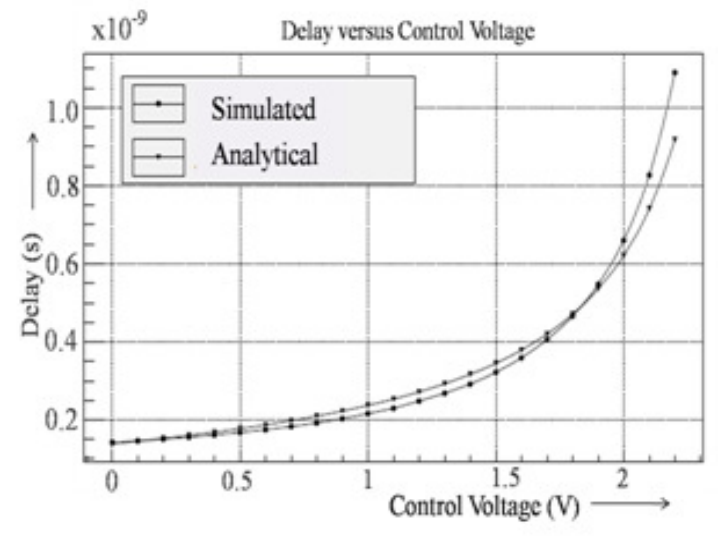

(b)

Figure 4. (a) $\mathrm{V}_{\mathrm{OL}}$ versus Control Voltage (b) Delay versus Control Voltage of MCBL delay element for simulated and analytical model

Table 1. Parameters and their values

\begin{tabular}{|l|l|}
\hline$\mu_{\mathrm{n}}=475 \mathrm{E}-4 \mathrm{~m}^{2} / \mathrm{V}-\mathrm{Sec}$ & $\mu_{\mathrm{p}}=148 \mathrm{E}-4 \mathrm{~m}^{2} / \mathrm{V}-\mathrm{Sec}$ \\
\hline $\mathrm{V}_{\mathrm{tn}}=0.5 \mathrm{~V}$ & $\mathrm{~V}_{\mathrm{tp}}=-0.69 \mathrm{~V}$ \\
\hline $\mathrm{C}_{\mathrm{ox}}=4.4 \mathrm{fF} / \mu \mathrm{m}^{2}$ & $\mathrm{~V}_{\mathrm{DD}}=3.3 \mathrm{~V}$ \\
\hline $\mathrm{T}=27^{0} \mathrm{C}=300 \mathrm{~K}$ & $\mathrm{~K}_{\mathrm{p}}=0.000651 .2 \mathrm{~F} / \mathrm{V}-\mathrm{sec}$ \\
\hline$\lambda=0.13 \mathrm{~V}^{-1}$ & $\mathrm{C}_{\mathrm{load}}=14 \mathrm{fF}$ \\
\hline$(\mathrm{W} / \mathrm{L})_{\mathrm{M} 3}=(\mathrm{W} / \mathrm{L})_{\mathrm{M} 4}=1 \mu / 0.35 \mu$ & $(\mathrm{W} / \mathrm{L})_{\mathrm{M} 1}=(\mathrm{W} / \mathrm{L})_{\mathrm{M} 2}=1.5 \mu / 0.35 \mu$ \\
\hline
\end{tabular}

\section{DESIGN OF DLL USING THE MCBL DELAY ELEMENT}

In this section, the functionality of MCBL delay element has been verified by realizing a DLL. The block diagram of DLL is shown in Figure 5 (a), where the designed key building blocks are Voltage Controlled Delay Line (VCDL), bias circuit, Phase Detector (PD), Charge Pump (CP), loop filter capacitor $(16 \mathrm{pF})$ and start control circuit.

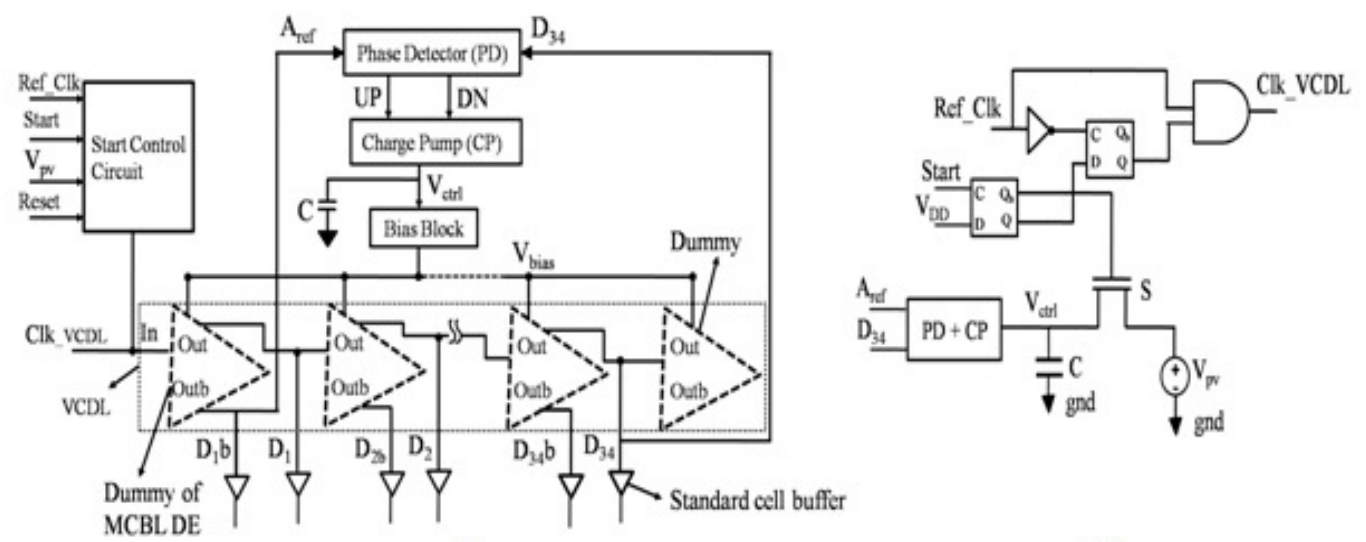

(a)

(b)

Figure 5. (a) Block diagram of DLL (b) Schematic diagram of start control circuit 
The VCDL is realised by $\mathrm{N}$ cascaded MCBL delay elements. The number $\mathrm{N}=33$ is calculated using equation (11), where, $T_{\text {ref }}=10 \mathrm{~ns}$ is the reference clock period and $T_{d}=150 \mathrm{ps}$ is unit target delay. The delay elements are loaded with standard cell buffers. To provide the identical load environment, two dummy delay elements at the beginning and end of VCDL are used.

$$
N=\frac{T_{r e f}}{2 \times T_{d}}
$$

The start control circuit shown in Figure 5(b) is designed to avoid false harmonic locking of DLL. It sets the initial voltage ' $\mathrm{V}_{\mathrm{pv}}$ ' (preset voltage) of loop filter capacitor before the commencement of locking process. Initially, the preset switch ' $\mathrm{S}$ ' is on. It sets the voltage across loop filter capacitor ' $\mathrm{C}$ ' to the voltage ' $\mathrm{V}_{\mathrm{pv}}$ ' $=0.5 \mathrm{~V}$ for unit delay of $170 \mathrm{ps}$. The value of ' $\mathrm{V}_{\mathrm{pv}}$ ' is deduced from delay characteristic of DE with bias circuit as shown in Figure 7(b). The bias circuit shown in Figure 6(a) modifies delay versus control voltage characteristic. It improves the range of control voltage and makes the delay a monotonic function with respect to control voltage.

The operation of DLL starts with the assertion of 'Start' signal. It turns off the preset switch ' $S$ ' and enables the reference clock 'Ref_Clk' inside VCDL. The delayed output clock ' $\mathrm{D}_{34}$ ' from VCDL is applied to PD shown in Figure 6(b), where its rising edge is compared with the rising edge of reference clock $A_{\text {ref }}$ (Figure 5(a)). The PD converts the phase error into equivalent time duration pulse 'UP' and 'DN'. The output of PD controls the charge pump [12]. If phase error is positive, the time duration error is given by UP signal, which controls the discharging of filter capacitor. If phase error is negative, it is given by DN signal, which controls the charging of filter capacitor. For the applied $\mathrm{V}_{\mathrm{pv}}$, the control voltage ' $\mathrm{V}_{\text {ctrl }}$ ' decreases by the correction of loop and stabilizes at $0.3 \mathrm{~V}$ for unit delay of $150 \mathrm{ps}$ as shown in Figure 8(a). After iterations of 20 clock cycles, the DLL locks the delay of VCDL to half clock period $(5 \mathrm{~ns})$ of reference clock.

The advantage of this delay element is that, only one control loop (including PD, charge pump, filter capacitor, and bias circuit) is required to control both rising and falling edge delays. The output of VCDL provides delayed replicas ' $\mathrm{D}_{1}$ ' to ' $\mathrm{D}_{34}$ ' of Clk_VCDL with time interval of 150 ps.

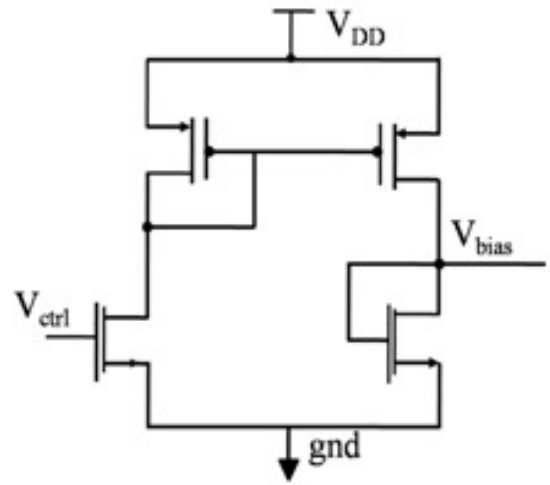

(a)

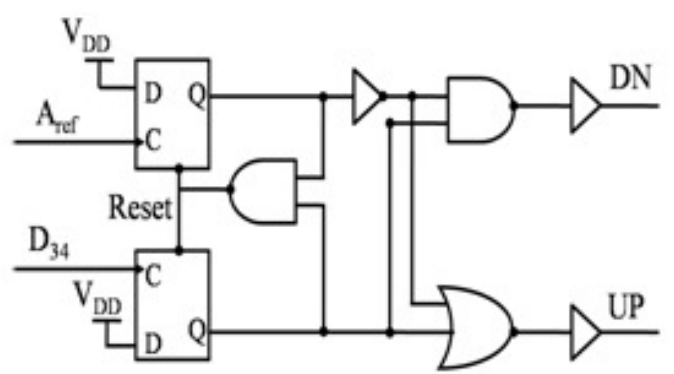

(b)

Figure 6. Schematic Diagram of (a) Bias Circuit (b) Phase Detector

\section{SimUlation RESULTS}

The MCBL delay element is implemented using $0.35 \mu \mathrm{m}$ CMOS technology. The results presented in this section are based on post layout simulation by Spectre using device models of standard CMOS process. The area of unit delay cell is $10 \times 10 \mu \mathrm{m}^{2}$. The static current of single DE is $140 \mu \mathrm{A}$ at $0.5 \mathrm{~V}$ control voltage. The static current reduces with the increment in control voltage. 
International Journal of VLSI design \& Communication Systems (VLSICS) Vol.5, No.3, June 2014

A linear sweep of control voltage in the range of $0 \mathrm{~V}$ to $3.3 \mathrm{~V}$ with a step size of $0.1 \mathrm{~V}$ is applied to bias circuit. Figure 7(a) shows the bias voltage over the range of control voltage from $0 \mathrm{~V}$ to $3.3 \mathrm{~V}$. The bias voltages applied to delay element causes identical variation in rising and falling edge delays of delay element. Figure 7(b) shows the plot of delay versus control voltage on typical corner.

The transient response of control voltage on typical corner is shown in Figure 8(a). Figure 8(b) depicts the consecutive uniformly delayed replicas of clock $D_{1}$ to $D_{9}$ generated from VCDL. In Table 2, the performance of delay element is compared with the other existing architectures in $0.35 \mu \mathrm{m}$ CMOS technology.

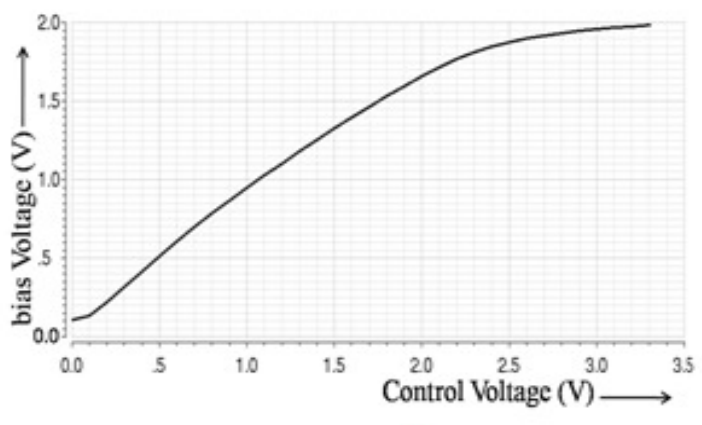

(a)

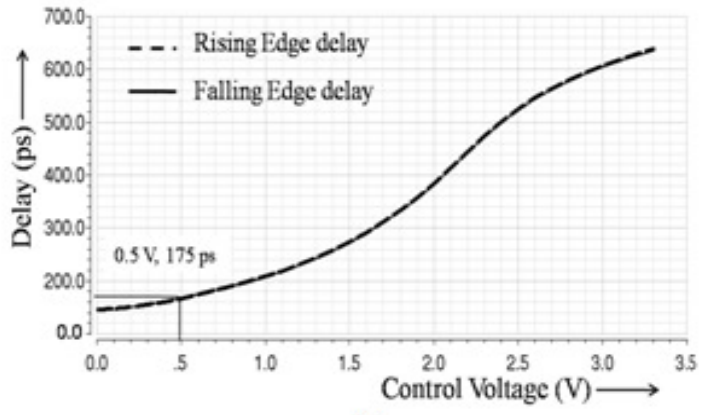

(b)

Figure 7. (a) Bias voltage $\left(\mathrm{V}_{\text {bias }}\right)$ with respect to control voltage (b) Delay with respect to control voltage

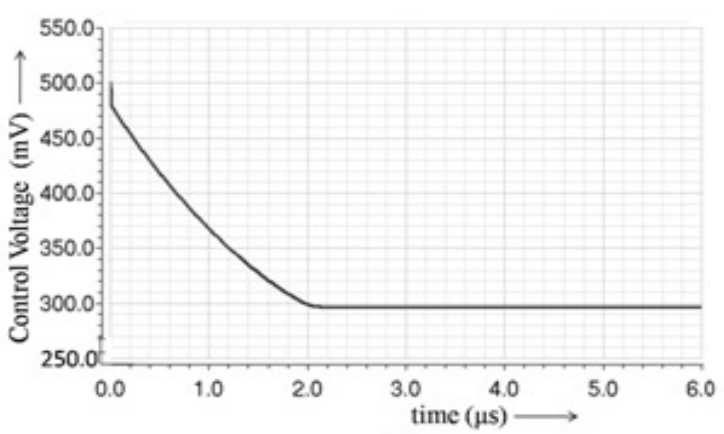

(a)

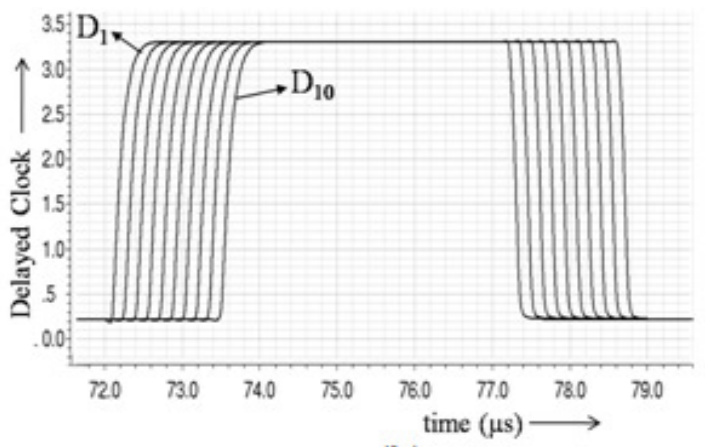

(b)

Figure 8. (a) Profile of Control Voltage ' $\mathrm{V}_{\text {ctrl }}$ ' of DLL (b) Delayed clocks generated from VCDL

Table 2. Performance Comparison

\begin{tabular}{|l|l|l|l|l|}
\hline DE & $\begin{array}{l}\text { This } \\
\text { Work }\end{array}$ & {$[\mathbf{6}]$} & {$[\mathbf{8}]$} & {$[\mathbf{1 0}]$} \\
\hline Type & $\begin{array}{l}\text { MCBL with bias } \\
\text { circuit }\end{array}$ & $\begin{array}{l}\text { Current Starved } \\
\text { INV }\end{array}$ & Differential & $\begin{array}{l}\text { Differential } \\
\text { (SCL) }\end{array}$ \\
\hline $\mathrm{T}_{\min }(\mathrm{ps})$ & 140 & 244 & 2500 & 29.3 \\
\hline $\mathrm{T}_{\max }(\mathrm{ps})$ & 680 & ---- & 16000 & ---- \\
\hline $\begin{array}{l}\text { Power with } \\
\text { DLL }\end{array}$ & $\begin{array}{l}25 \mathrm{~mW} @ 100 \\
\mathrm{MHz}\end{array}$ & $\begin{array}{l}14 \mathrm{~mW} @ 32 \\
\mathrm{MHz}\end{array}$ & $\begin{array}{l}132 \mathrm{~mW} \text { @ 130 } \\
\mathrm{MHz}\end{array}$ & $\begin{array}{l}675 \mathrm{~mW} \text { (without 3 V } \\
\text { (with) }\end{array}$ \\
\hline $\mathrm{N}$ & 33 & 128 & 10 & 64 \\
\hline Swing & Full & Full & Partial & Partial \\
\hline Process & $0.35 \mu \mathrm{m}$ & $0.35 \mu \mathrm{m}$ & $0.35 \mu \mathrm{m}$ & $0.35 \mu \mathrm{m}$ \\
\hline
\end{tabular}


International Journal of VLSI design \& Communication Systems (VLSICS) Vol.5, No.3, June 2014

\section{CONCLUSION}

In this paper, a MCBL delay element and its analysis is presented. The analytical delays sufficiently match with the simulated ones. This delay element attains small propagation delays 147 ps with large swing and relatively low static current $(140 \mu \mathrm{A} @ 0.5 \mathrm{~V})$. It provides identical rising and falling edge delays, which enables us to control both delays with a single control loop. This DE can be interfaced with the standard cells as the maximum value of $\mathrm{V}_{\mathrm{OL}}$ is $0.25 \mathrm{~V}$ at $0.1 \mathrm{~V}$ control voltage. This delay element has potential to be incorporated in the mixed signal design due to MCBL logic.

\section{REFERENCES}

[1] S. Eto, H. Akita, et al., (2000), “A 333MHz, 20mW, 18ps resolution digital DLL using current controlled delay with parallel variable resistor DAC," in Proceeding, 2nd IEEE Asia Pacific Conference on ASIC, pp. 349-350.

[2] J. Dunning, J. Lundberg, et al., (1995) "An all digital phase locked loop with 50-cycle lock time suitable for high performance microprocessors," IEEE Journal of Solid-Sate Circuits, vol. 30, pp. 412-422.

[3] M. G. Johnson, E. L. Hudson, et al., (1998) "A variable delay line PLL for CPU-Coprocessor synchronization,” IEEE Journal of Solid-State Circuits, vol. 23, pp. 1218-1223.

[4] M. Mota; (2000), "Design and Characterization of CMOS High-Resolution Time-to-Digital Converters," Ph.D thesis, Microelectronics Group, CERN, Geneva.

[5] Nihar R. Mahapatra, et al., (2002), "Comparison and analysis of delay elements," IEEE symposium on circuits and systems, Vol.2.

[6] O. Bourrion, L. Gallin-Martel, (2006) "An integrated CMOS Time-to-digital converter for coincidence detection in a liquid Xenon PET prototype", Nuclear Instruments and Methods in physics research section A, Volume 563, issue 1,pp 100-103.

[7] Rabey, 'Digital Integrated Circuits-A design Perspective (2nd Edition), Lumped RC-Model, Chapter4

[8] H. Chang, J.Lin, and C. Yang, et al. (2002), "A wide-range delay-locked loop with a fixed latency of one clock cycle", IEEE Journal of Solid-State Circuits, vol.37, pp 1021-1027.

[9] Amir Ghaffari and Adib Abrisshamifar, (2006) "A Novel Wide-Range Delay Cell for DLL's," International Conference on Electrical and Computer Engineering, pp.497-500.

[10] Andras Mozsary, Jen-Feng Chung et al. (2006), "Bio-Inspired 0.35um CMOS Time-to-Digital Converter with 29.3ps LSB”, 32-European Solid State Circuit Conference, pp.170-173.

[11] E. Albuquerque et al. (1999), "Current-Balanced Logic for Mixed Signal IC's," Proceeding of the IEEE International Symposium on Circuit and System, pp. I.274-I.277

[12] Sukhwani Menka, Chandrate V.B. et al. (2011), "500 MHz Delay Lock Loop based 128-bin, 256 ns deep analog memory ASIC, Anusmriti”, Proceeding of IEEE symposium on Computer Society. 